\title{
Impact of climate change on extreme rainfall events and flood risk in India
}

\author{
P Guhathakurta*, O P Sreejith and P A Menon \\ India Meteorological Department, Shivajinagar, Pune 411 005, India. \\ *e-mail: pguhathakurta@rediffmail.com
}

The occurrence of exceptionally heavy rainfall events and associated flash floods in many areas during recent years motivate us to study long-term changes in extreme rainfall over India. The analysis of the frequency of rainy days, rain days and heavy rainfall days as well as one-day extreme rainfall and return period has been carried out in this study to observe the impact of climate change on extreme rainfall events and flood risk in India. The frequency of heavy rainfall events are decreasing in major parts of central and north India while they are increasing in peninsular, east and north east India. The study tries to bring out some of the interesting findings which are very useful for hydrological planning and disaster managements. Extreme rainfall and flood risk are increasing significantly in the country except some parts of central India.

\section{Introduction}

In recent years, heavy precipitation events have resulted in several damaging floods in India. The consecutive flash floods over three major metro cities in the same year, i.e., Mumbai in July 2005, Chennai in October 2005 and again in December 2005 and Bangalore in October 2005 caused heavy damages in economy, loss of life, etc. Some of the recent studies (Goswami et al 2006; Rajeevan et al 2008) on extreme rainfall events over India were mostly concentrated in central India. Regions where the country recently experienced extreme rainfall events such as $94 \mathrm{~cm}$ in Mumbai, $156.5 \mathrm{~cm}$ (country's highest ever recorded one-day point rainfall) in Cherrapunji, or Chennai or Bangalore were not included in the studies. A detailed study on extreme rainfall events covering the entire region and using the latest data is urgently needed to obtain a clear idea about the impact of climate change on the extreme weather events of the country. It may be mentioned that understanding the changes in extremes weather events is more important than the changes in mean pattern for better disaster management and mitigation. According to the latest report of Intergovernmental Panel on Climate Change (IPCC 2007), another aspect of the projected changes is that "wet extremes are projected to become more severe in many areas where mean precipitation is expected to increase, and dry extremes are projected to become more severe in areas where mean precipitation is projected to decrease. In the Asian monsoon region and other tropical areas there will be more flooding".

A large amount of the variability of rainfall is related to the occurrence of extreme rainfall events and their intensities. Therefore, there is a need to know the magnitudes of extreme rainfall events over different parts of the area under study. The study of spatial variability of extreme rainfall events help to identify zones of high and low values of extreme rainfall events. A detailed regionalized study is practically useful for planners and other users. Sinha Ray and Srivastava (2000) have done

Keywords. Climate changes; extreme rainfall events; flood risk. 
trend analysis of heavy rainfall events over selected stations all over India and reported a decreasing trend over most parts of the country. However, over northern west coast and a few stations in the northern parts (Haryana and Punjab), a significant increasing trend was found. Earlier, Rakhecha and Pisharoty (1996) have studied heavy rainfall events during southwest monsoons for some selected stations in the country. Rakhecha and Soman (1994) analysed the annual extreme rainfall series in the timescale of 1 to 3 days at 316 stations, well distributed over the country, covering 80 years of rainfall data from 1901 to 1980 for trends and persistence using standard statistical tests. They have reported that the annual extreme rainfall records of most stations are free from trends and persistence. However, the extreme rainfall series at stations over the west coast, north of $12^{\circ} \mathrm{N}$ and at some stations to the east of the Western Ghats over the central parts of the peninsula showed a significant increasing trend at $95 \%$ level of confidence. Stations over the southern peninsula and over the lower Ganga valley exhibit a decreasing trend at the same level of significance. Stephenson et al (1999) using the data for the period June to September 1986-1989 have investigated extreme daily rainfall events and their impact on ensemble forecasts of the Indian monsoon. Most of the studies on extreme rainfall over India (Rakhecha and Soman 1994; Sen Roy and Balling 2004) used limited number of stations. Sen Roy and Balling (2004) have considered parameters such as total annual precipitation, 5-day total precipitation and 30-day total precipitations in their extreme rainfall analysis. In our study, we have considered four indices which are directly related to extreme rainfall events. The results are very useful for further studies and disaster management. Recently, Goswami et al (2006) using the daily gridded data of India Meteorological Department for the period 1951-2003, examined the trend of extreme rainfall over India. However their study was confined to the central India. In their study, they have reported an increase in the frequency and the magnitude of extreme rain events and a significant decreasing trend in the frequency of moderate events over central India. It may be noted that for extreme rainfall analysis to study the behaviour of changes in the extreme events, real or actual station data is more realistic than the gridded dataset. In the gridded datasets, extreme events will not be captured on most of the occasions due to interpolation or averaging scheme used in gridding. This can even mislead the signals of hydrological extremes for better disaster management. Rajeevan et al (2008) used 104 years of gridded dataset and selected a box mostly comprising central India similar to
Goswami et al (2006) and examined the variability and long-term trends of extreme rainfall events.

This study aims to analyse some of the extreme rainfall indices using reliable, consistent and sufficient amount of rain gauge station data and to study the changes in the frequency of rainy days, rain days as well as heavy rainfall days. Oneday extreme rainfall analysis was also performed to study the changes in the intensity of extreme weather events. Increasing flood risk is now recognized as the most important sectoral threat from climate change in most parts of the world. Temporal variability in extremes is analysed for fixed decades from 1951-1960, 1961-1970, 1971-1980, 1981-1990 and 1991-2000. Return period analysis is used to analyse the changing probability of extreme rainfall events for observed data in order to find out the changes in flood risk.

\section{Data and methodology}

Daily rainfall data for the period 1901-2005 in more than 6000 rain gauge stations all over India were considered initially. The data was collected from India Meteorological Department, Pune. From a network of stations, 2599 stations having 30 years or more data were selected. Selecting a large network of stations having maximum data availability (Fowler et al 2000; Fowler and Kilsby 2002 , etc.) helps better spatial representation instead of using fewer number of stations with uniform data availability.

Annual time series of the following indices are constructed for these stations.

- Frequency of rainy days. According to the definition followed by India Meteorological Department, a day is called 'rainy day', if the rainfall of that day is $2.5 \mathrm{~mm}$ or more.

- Frequency of rain days. A day is considered as 'rain day' if the amount of rainfall of that day is $0.1 \mathrm{~mm}$ or more.

- Frequency of heavy rainfall days (including very heavy and extremely heavy). A day is called 'heavy rainfall day' if the rainfall of that day is $64.5 \mathrm{~mm}$ or more according to India Meteorological Department. This includes very heavy (i.e., $124.5-244.5 \mathrm{~mm}$ ) and extremely heavy (i.e., $>244.5 \mathrm{~mm}$ ) rainfall.

- Annual one-day extreme rainfall series. Annual one-day extreme rainfall is usually defined as the maximum daily rainfall within each year, so one would have as many extreme values as the total number of years.

While analysing the data it has been found that there were some missing observations in some years 

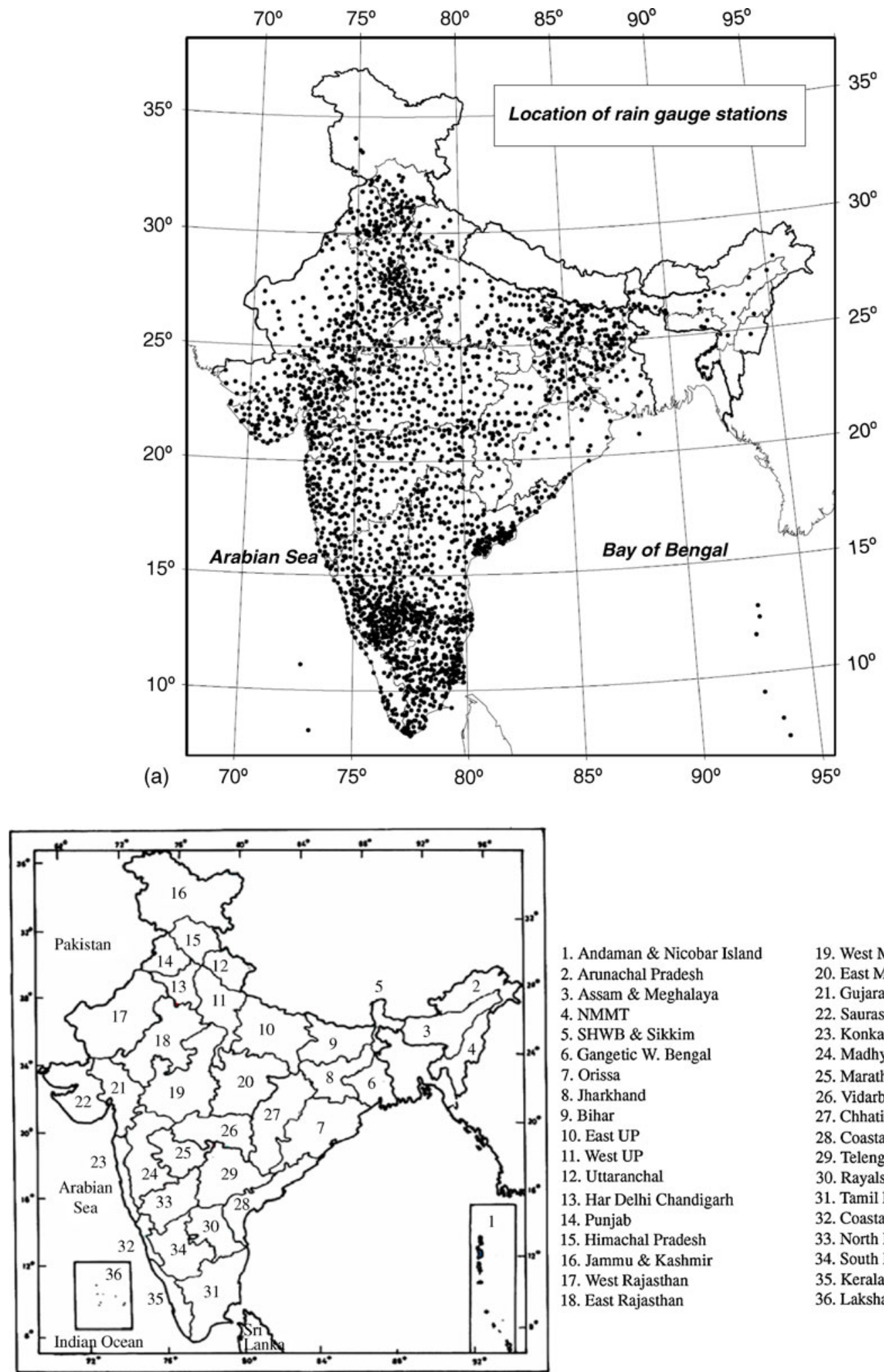

1. Andaman \& Nicobar Island

19. West MP

2. Arunachal Pradesh

20. East MP

3. Assam \& Meghalaya 21. Gujarat Region

4. NMMT

22. Saurashtra \& Kutch

SHWB \& Sikkim

23. Konkan \& Goa

6. Gangetic W. Bengal 24. Madhya Maharashtra

7. Orissa

8. Jharkhand

9. Bihar

25. Marathwada

26. Vidarbha

27. Chhatisgarh

28. Coastal AP

29. Telengana

30. Rayalseema

$\begin{array}{ll}\text { 2. Uttaranchal } & \text { 30. Rayalseema } \\ \text { 3. Tamil Nadu }\end{array}$

$\begin{array}{ll}\text { 13. Har Delhi Chandigarh } & \text { 31. Tamil Nadu } \\ \text { 14. Punjab } & \text { 32. Coastal Karnataka }\end{array}$

15. Himachal Pradesh

33. North Interior Karnataka

16. Jammu \& Kashmir 34. South Interior Karnataka

17. West Rajasthan $\quad 35$. Kerala

18. East Rajasthan

36. Lakshadweep

(b)

Figure 1. (a) Location of 2599 rain gauge stations over India. (b) Geographical location of India's 36 meteorological sub-divisions. 


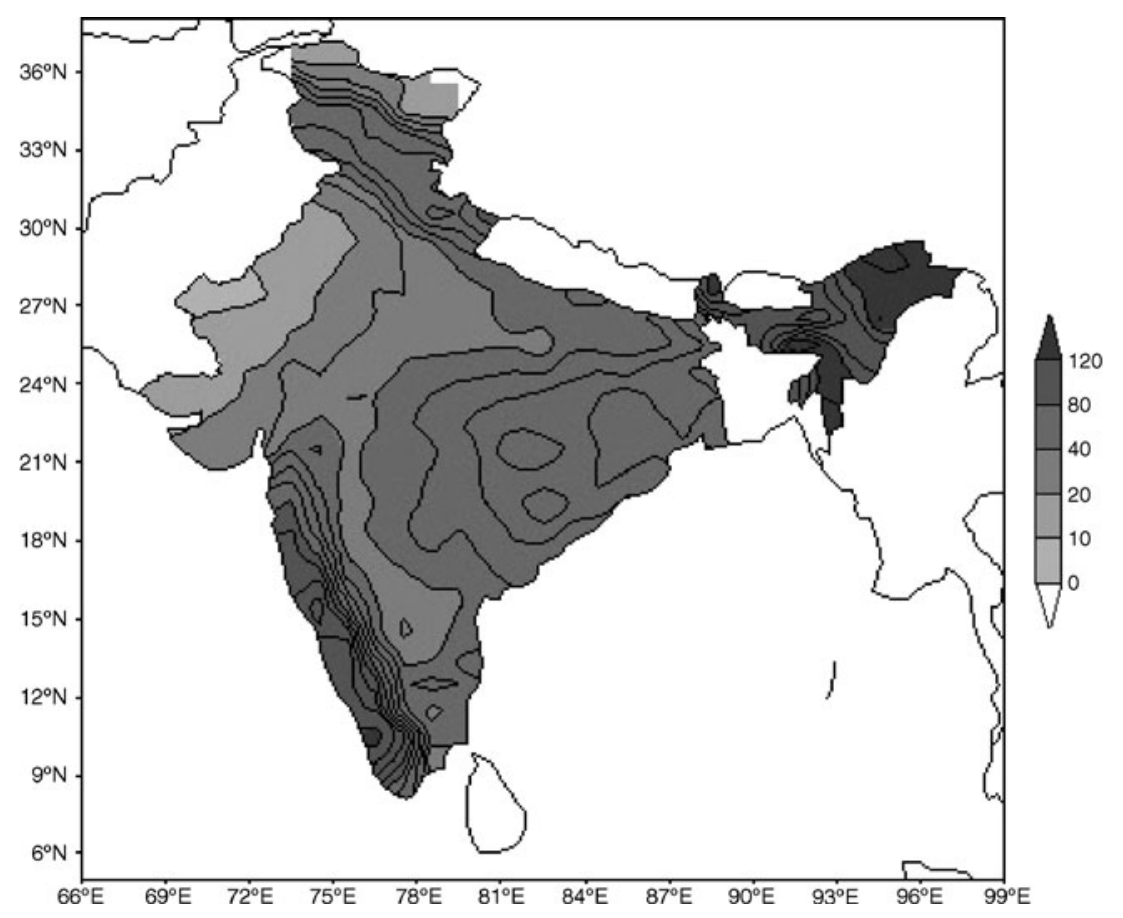

Figure 2. Annual frequency of normal rainy days.

of data. For the first three cases we have removed the effect of missing days observation by dividing the actual annual frequency with actual number of observation of that year and then multiplying by the number of days of that year. It may be mentioned that almost the same methodology is used by Sen Roy and Balling (2004) to remove the effect of missing years.

Recent studies indicate that the most widely used method for detecting the trend is the nonparametric Mann-Kendall (MK) trend test. Mann (1945) originally derived the test and Kendall (1975) subsequently derived the test statistic commonly known as the Kendall's tau statistic. It was found to be an excellent tool for trend detection in different applications (Hirsch et al 1982; Lettenmaier et al 1994; Burn and Hag-Elnur 2002).

Under the null hypothesis H0, a series $\left\{x_{1}, \ldots\right.$, $\left.x_{N}\right\}$ are obtained from a population where the random variables are independent and identically distributed (i.e., null hypothesis has no trend), the MK test statistic is:

$$
S=\sum_{i=1}^{N-1} \sum_{j=i+1}^{N} \operatorname{sgn}\left(x_{j}-x_{i}\right)
$$

where

$$
\operatorname{sgn}(x)=\left\{\begin{aligned}
+1, & x>0 \\
0, & x=0 \\
-1, & x<0
\end{aligned}\right.
$$

And tau is estimated as:

$$
\tau=\frac{2 S}{N(N-1)}
$$

It may be mentioned that the MK trend test is a non-parametric test which allows missing data. It is not affected by gross data errors and outliers. However, this test can be used only as a yes/no test to detect the existence of a slope.

To determine the amount of increase or decrease in 100 years, we have adopted least square linear fit of the data. The advantage of linear regression is that it provides an estimate of slope, confidence interval and quantifies goodness of fit. However, it does not handle missing data and may be greatly affected by outliers and cyclic data. As mentioned earlier in our study we have removed the effect of missing days observation by dividing the actual annual frequency with actual number of observation days of that year and then multiplying by the number of days of that year.

To determine the flood risk, extreme values for 25, 50 and 100 years return period are calculated. Probabilistic extreme value theory, which primarily deals with the stochastic behaviour of the maximum and minimum random variables, extreme and intermediate order statistics and exceedance over (below) high (low) thresholds are determined by the underlying distribution.

Traditionally, the three extreme value distributions are applied to annual maximum daily rainfall. 

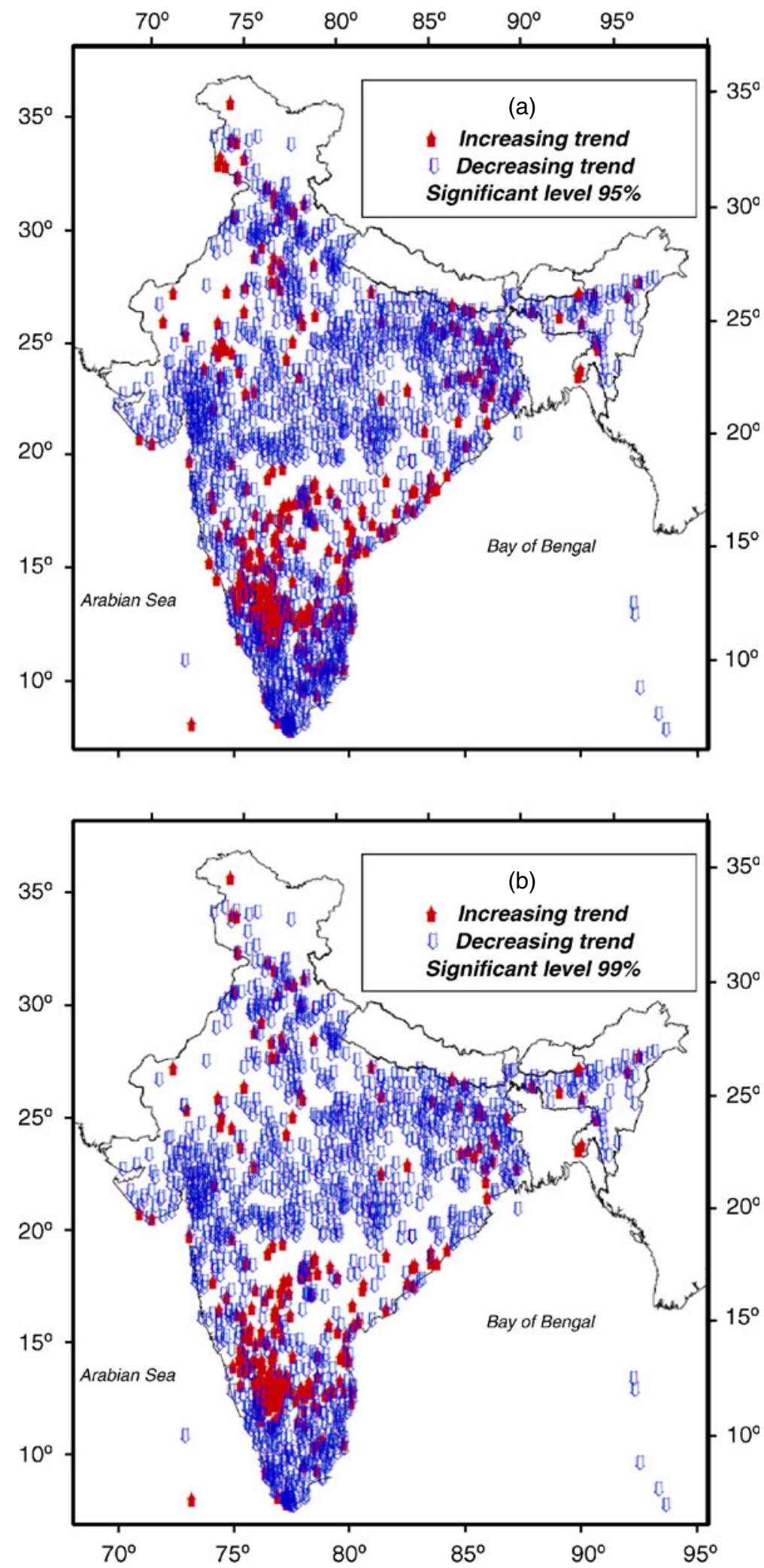

Figure 3. Stations with significant increasing/decreasing trend in frequency of rain days at (a) $95 \%$ significant level and (b) $99 \%$ significant level using MK non-parametric trend test. 

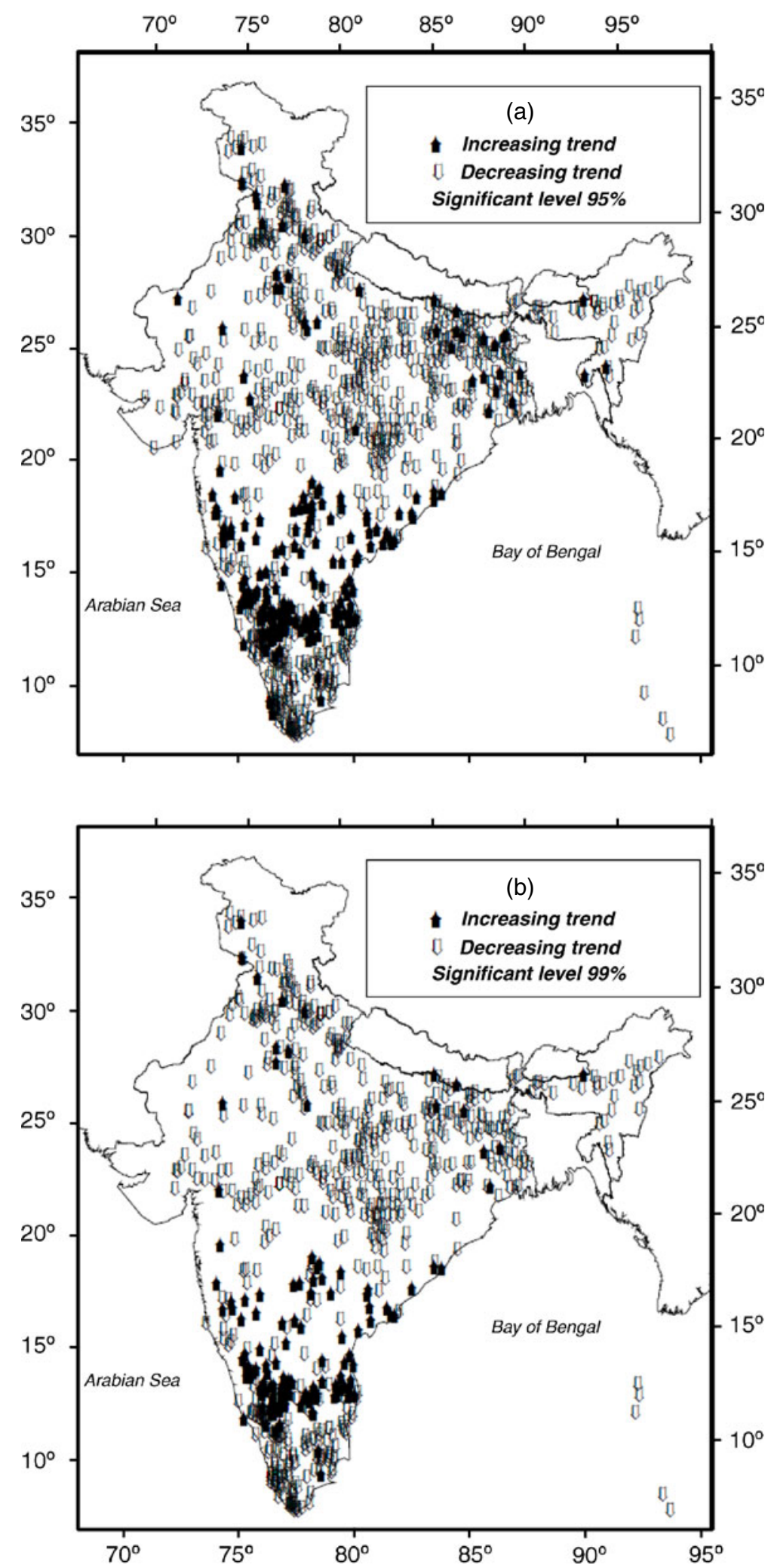

Figure 4. Stations with significant increasing/decreasing trend in frequency of rainy days at (a) $95 \%$ significant level and (b) $99 \%$ significant level using MK non-parametric trend test. 

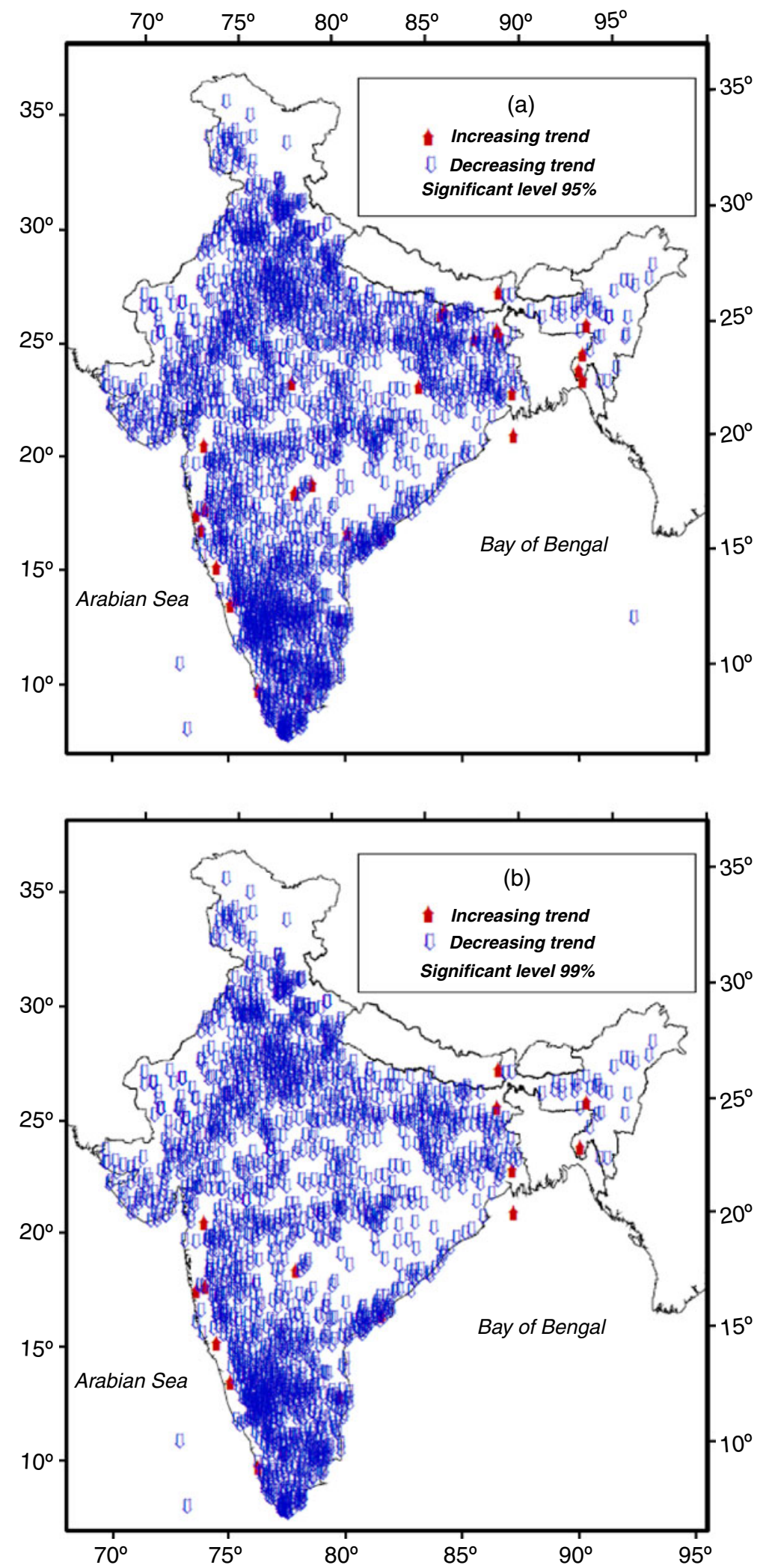

Figure 5. Stations with significant increasing/decreasing trend in frequency of heavy rainfall days at (a) $95 \%$ significant level and (b) $99 \%$ significant level using MK non-parametric trend test. 
In this paper, we have used the generalized extreme value (GEV) distribution, which has the flexibility of all the other extreme value distributions The GEV distribution was developed by Jenkinson (1955), Hosking et al (1985) and Galambos (1987). The cumulative distribution function (cdf) of the GEV distribution is as follows.

$$
F(x ; \psi, \beta)=\exp \left(-\left(1+\zeta \frac{x-\psi}{\beta}\right)^{-1 / \zeta}\right)
$$

for $1+\xi(x-\psi) / \beta>0$, where $\psi, \beta$ and $\xi$ are referred to as the location, scale and shape parameters, respectively. The particular case of (1) for $\xi \rightarrow 0$ is the Gumbel distribution

$$
F(x ; \psi, \beta)=e^{-e^{(\psi-x) / \beta}} .
$$

The median is $\psi-\beta \ln (-\ln (1 / 2))$.

The mean is $\psi+\gamma \beta$ where $\gamma=$ Euler-Mascheroni constant $\approx 0.5772156649015328606$.
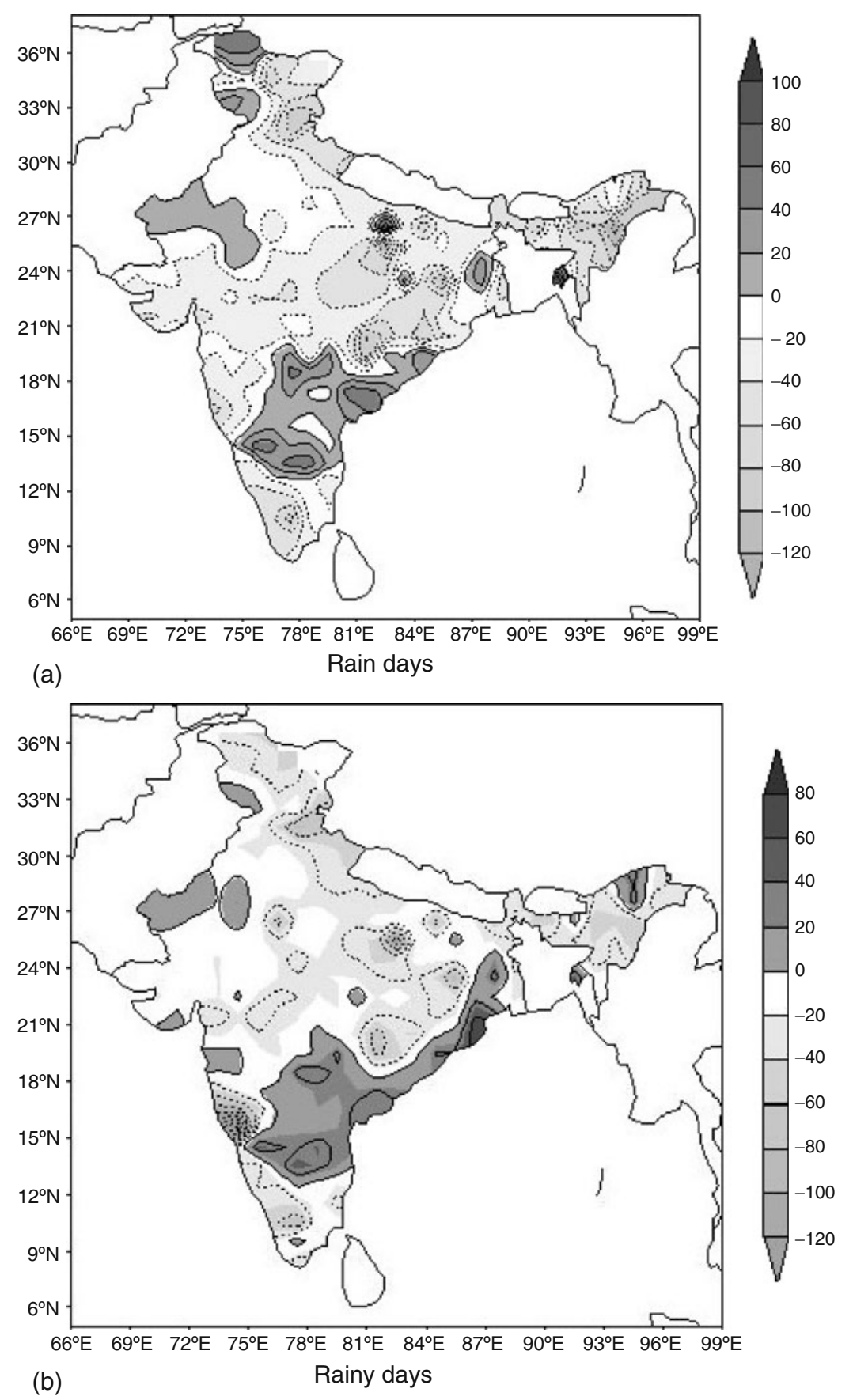

Figure 6. Increase/decrease in frequency of (a) rain days (b) rainy days and (c) heavy rainfall days in 100 years. 


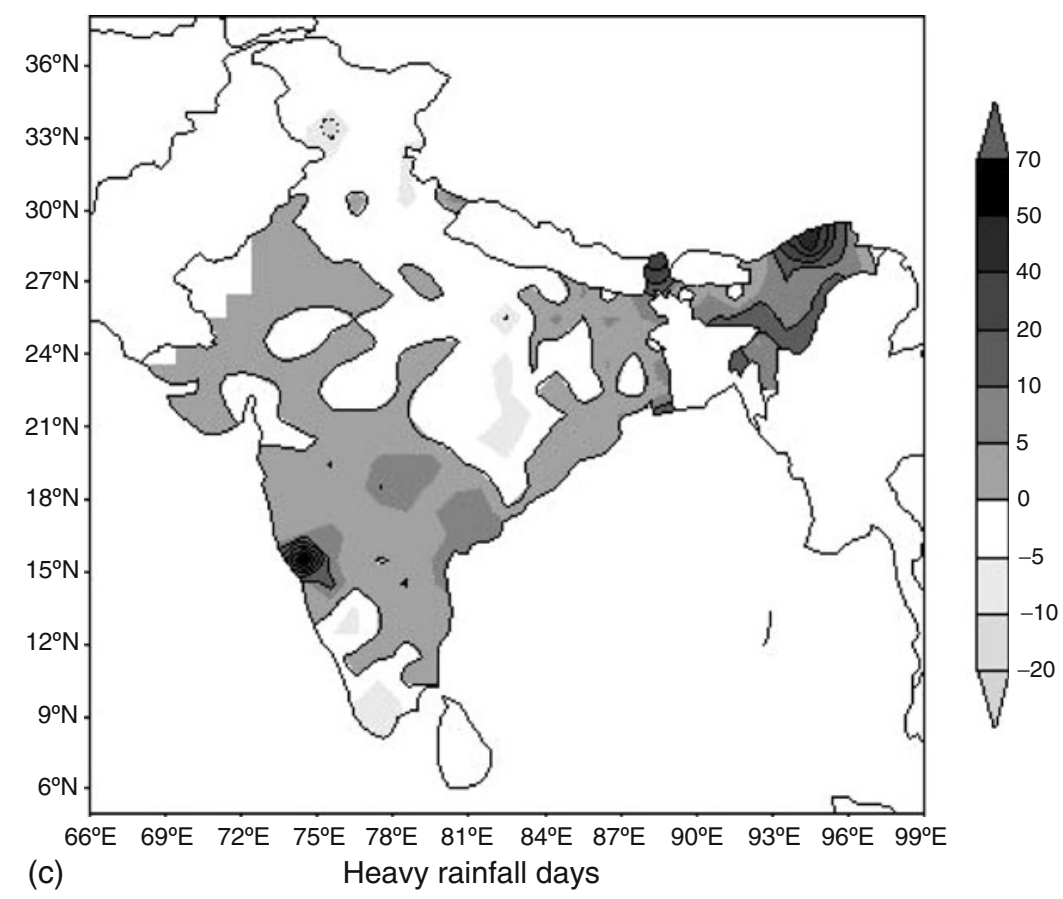

Figure 6. (Continued).

The standard deviation is:

$$
\beta \pi / \sqrt{6} \text {. }
$$

The mode is $\psi$.

Then from the Gumbel distribution with parameters $\psi$ and $\beta$, the extreme value (return value) $x$ for a period of $n$ years can be derived by the following formula:

$$
x=\psi-\beta \ln [-\ln (F)],
$$

where $\psi=$ average $-\gamma \beta$ (where $\gamma$ is Euler's constant, approximately 0.557 ).

$\beta=0.78 \sigma$ (where $\sigma$ is the standard deviation), $F$ is the random variate drawn from the uniform distribution in the interval $[0,1]=(n-1) / n$.

\section{Result and analysis}

India lies within the tropical monsoon zone and has a high spatial variation in rainfall and its frequencies. Figure 1(a) shows the location of 2599 rain gauge stations across the country which were considered for this study, while figure 1(b) shows the 36 meteorological sub-divisions of India. From the annual frequency of rainy days, rain days and heavy rainfall days; average or normal rainy days, rain days and heavy rainfall days were computed. High spatial variations in the climatology of frequency of rainy days can be seen in figure 2 . Annual normal rainy days vary from the low value of 10 over extreme western parts of Rajasthan to the high frequency of 130 days over northeastern parts of the country. The northeastern parts of the country as well as sub-Himalayan West Bengal and also extreme western coast line of the country received an average of more than 100 rainy days in a year.

Significant decreasing trends in the frequency of rain days, rainy days and heavy rainfall days can be seen over most parts of central, north and eastern parts of the country using both MK and $t$ tests. Figure $3(\mathrm{a}$ and $\mathrm{b})$ shows the decreasing/increasing trend of stations having significant at $95 \%$ and $99 \%$, respectively in the frequency of rain days obtained by using the MK test. Wet days have increased in peninsular India particularly over Karnataka, Andhra Pradesh and parts of Rajasthan and some parts of eastern India, while most parts of central and northern India showed a decreasing trend in frequency of rain days. Figure $4(\mathrm{a}$ and $\mathrm{b})$ shows the decreasing/increasing trend of stations having significant at $95 \%$ and $99 \%$, respectively in the frequency of rainy days obtained by using the MK test. Figure $5(\mathrm{a}$ and $\mathrm{b})$ shows the decreasing/increasing trend of stations having significant at $95 \%$ and $99 \%$, respectively in the frequency of heavy rainfall days obtained by using the MK test. Almost similar patterns of trends that were observed in frequency of rain days in figure 3 are also observed in the frequency of rainy days in figure 4 with some differences. Significant increasing trends are clearly noticed in the frequency of rain days over eastern Rajasthan, however, these 
increasing trends were not maintained in the frequency of rainy days. These imply that although number of wet days are increasing over eastern Rajasthan, occurrences of rain are not intensified. Increasing trends in the frequency of heavy rainfall days are observed in very few stations mostly in Konkan and Goa and adjoining regions of western coast and some isolated stations of eastern India. Frequency of heavy rainfall events decreased significantly for most parts of the country. Figure 6 shows the contour analysis on the rate of decrease/increase, i.e., slopes in the frequency of rain days, rainy days and heavy rainfall days in 100 years significant at $95 \%$ level obtained by using linear regression. The rate of increase in rain days has been observed to be around 40 to 50 days in 100 years in peninsular India particularly over Karnataka and Andhra Pradesh. Increase in rain days has also been observed over most parts of Rajasthan, parts of gangetic West Bengal and adjoining parts of Jharkhand. This indicates that the great desert areas of India are becoming wet. It may be mentioned that Guhathakurta and Rajeevan (2008) have also reported an increasing trend in the annual mean rainfall of these regions. However, extreme southern parts of the country, i.e., Kerala and Tamil Nadu are experiencing more dry days. Decreasing trends in annual mean rainfall over Kerala and Tamil Nadu have also been reported by Guhathakurta and Rajeevan (2008). Figure 6(c) clearly indicates that frequency of extreme rainfall events has decreased in most of central and north India. It may be mentioned that Goswami et al (2006) reported significant increasing trends in the frequency of extreme events over central India using gridded data. This is because they have studied extreme rainfall with a gridded dataset. Maximum increase in the frequency of heavy rainfall events (20 to 50 days in 100 years) has been noticed in northeast India and coastal Karnataka. The country's highest observed oneday point rainfall and also world's highest two-day point rainfall occurred in Cherrapunji of northeast India in 1995 (Guhathakurta 2007).

Figure 7 gives the spatial pattern of India's highest one-day ever recorded point rainfall. Occurrences of $40 \mathrm{~cm}$ or more rainfall has been noticed along the west and east coast of India, Gangetic West Bengal and northeastern parts of India. Trend analysis was performed over an annual oneday extreme rainfall series for each of the stations. Figure $8(\mathrm{a}$ and $\mathrm{b})$ shows the increasing/decreasing

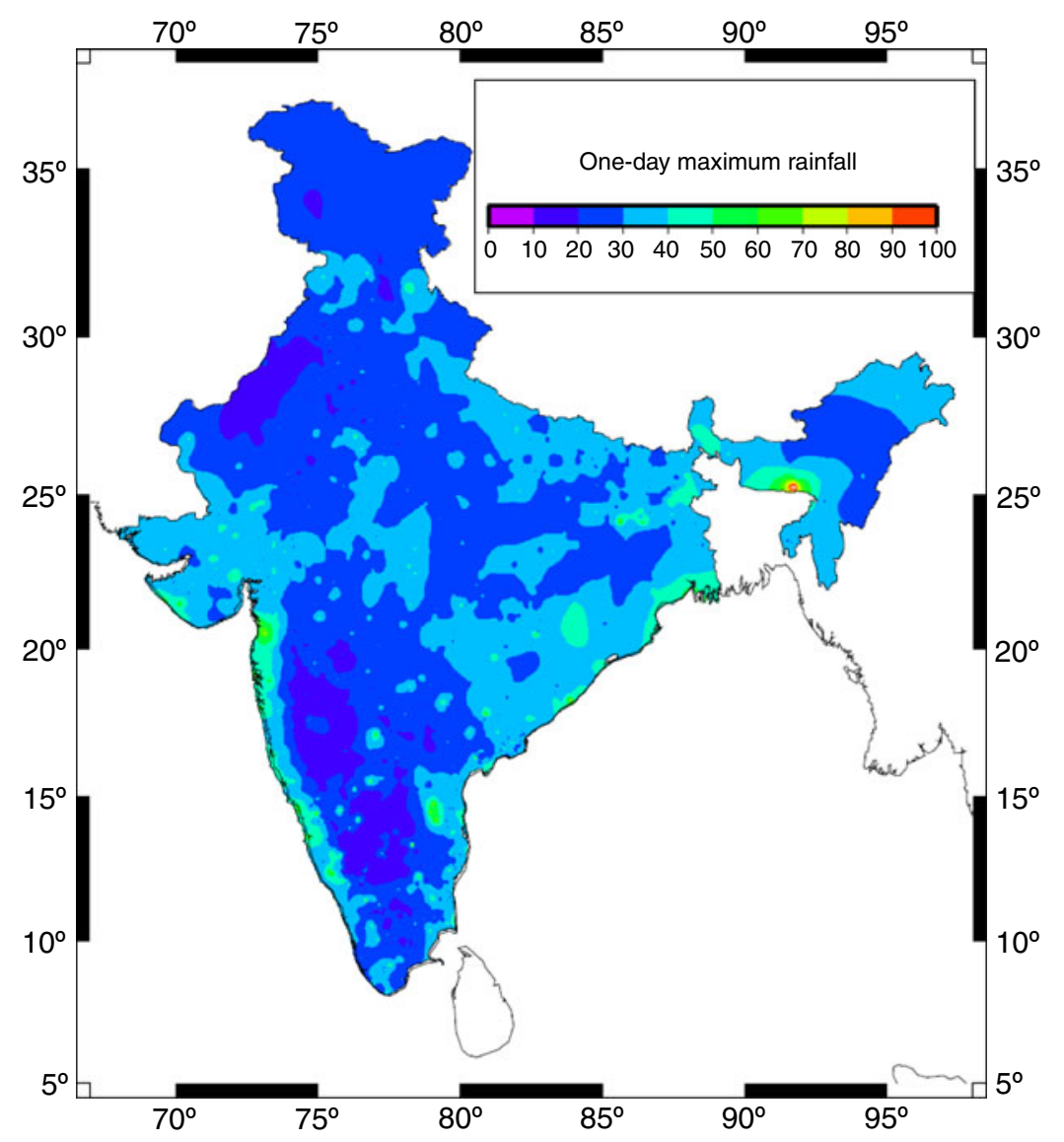

Figure 7. Highest one-day extreme rainfall in India. 

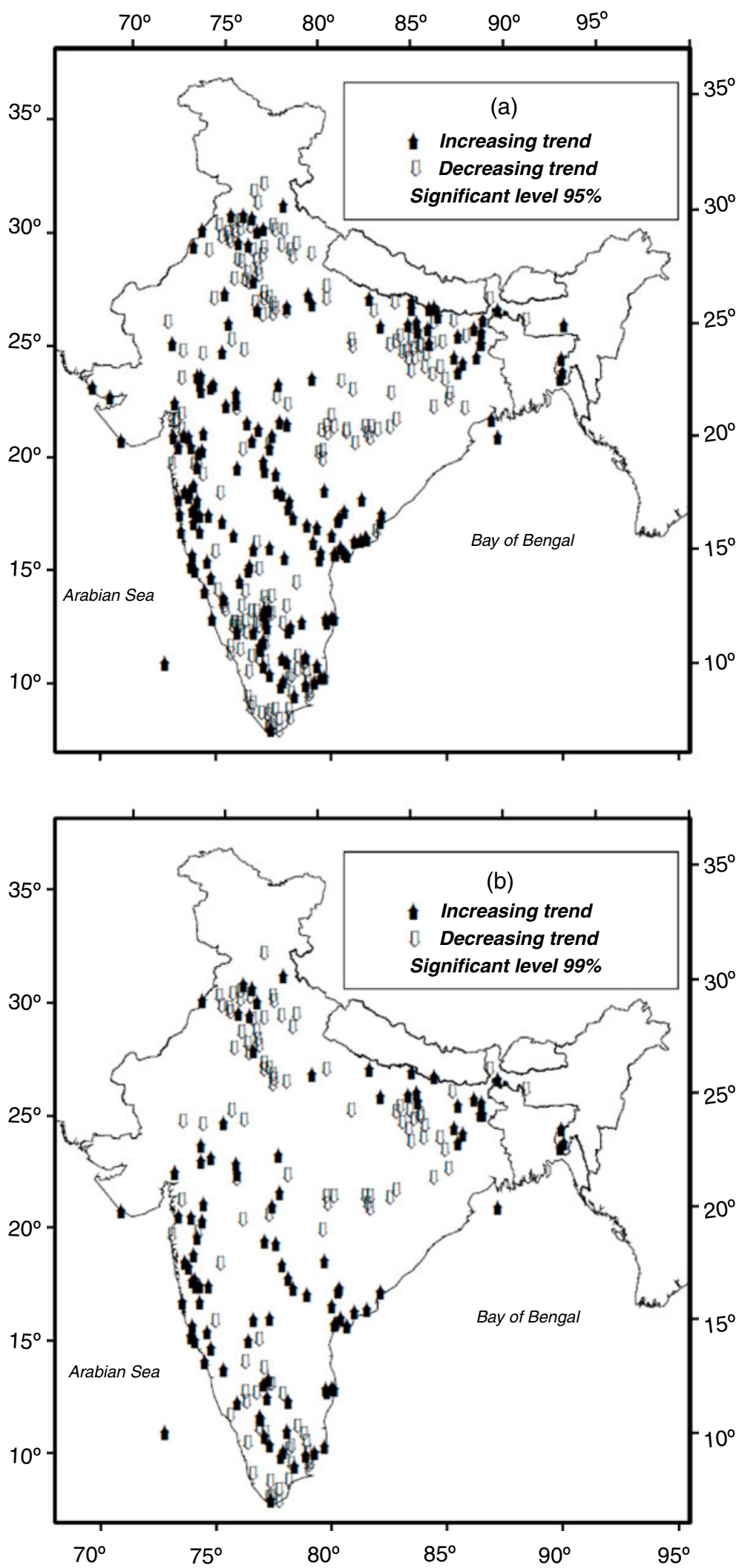

Figure 8. Stations with significant increasing/decreasing trend in one-day extreme rainfall at (a) 95\% significant level and (b) $99 \%$ significant level using MK non-parametric trend test.

trend of stations having significant at $95 \%$ and $99 \%$, respectively in the one-day extreme rainfall obtained by using the MK test. The non- parametric test shows significant increasing trend in one-day extreme rainfall over the south peninsular region, Maharashtra, Gujarat region, Bihar 


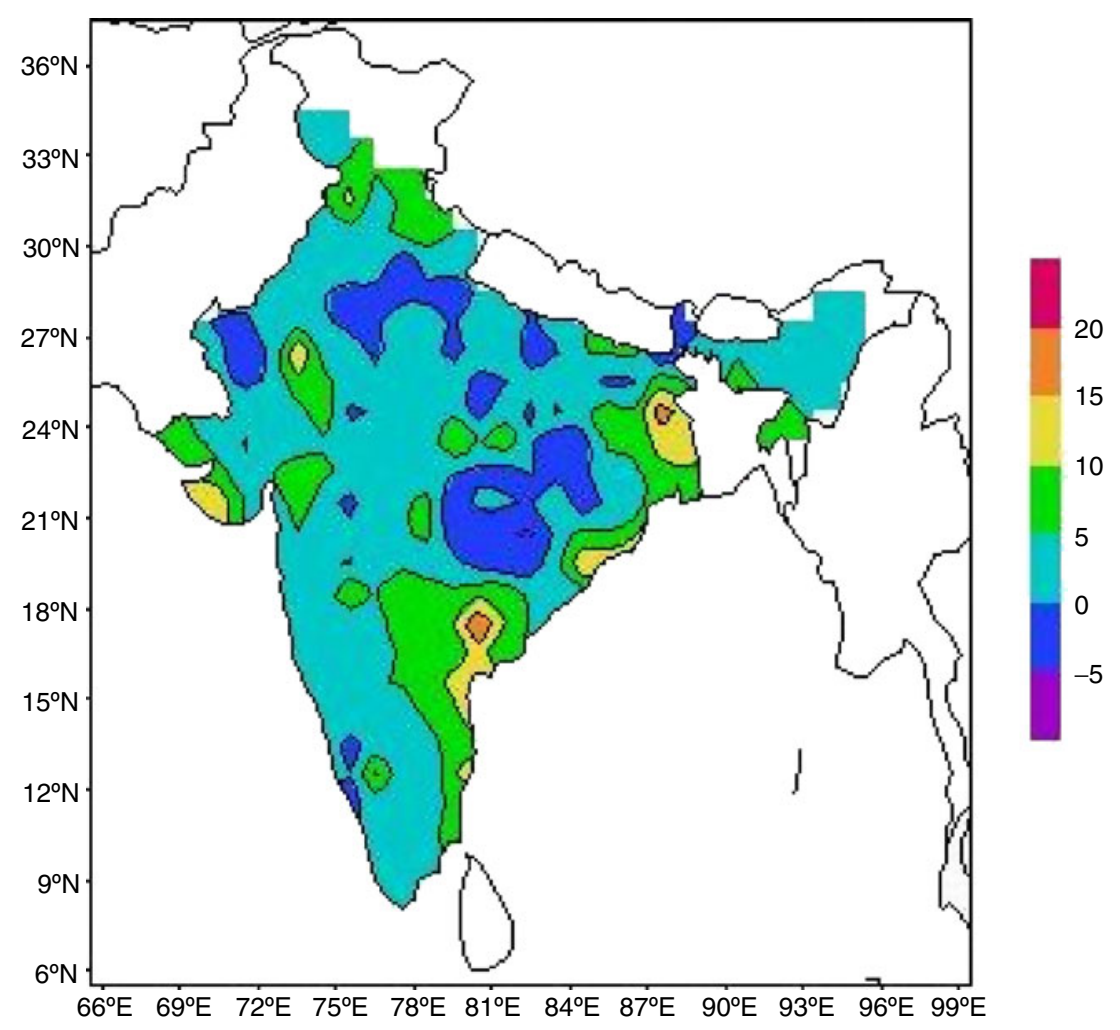

Figure 9. Increase/decrease in one-day extreme rainfall $(\mathrm{cm})$ in 100 years.

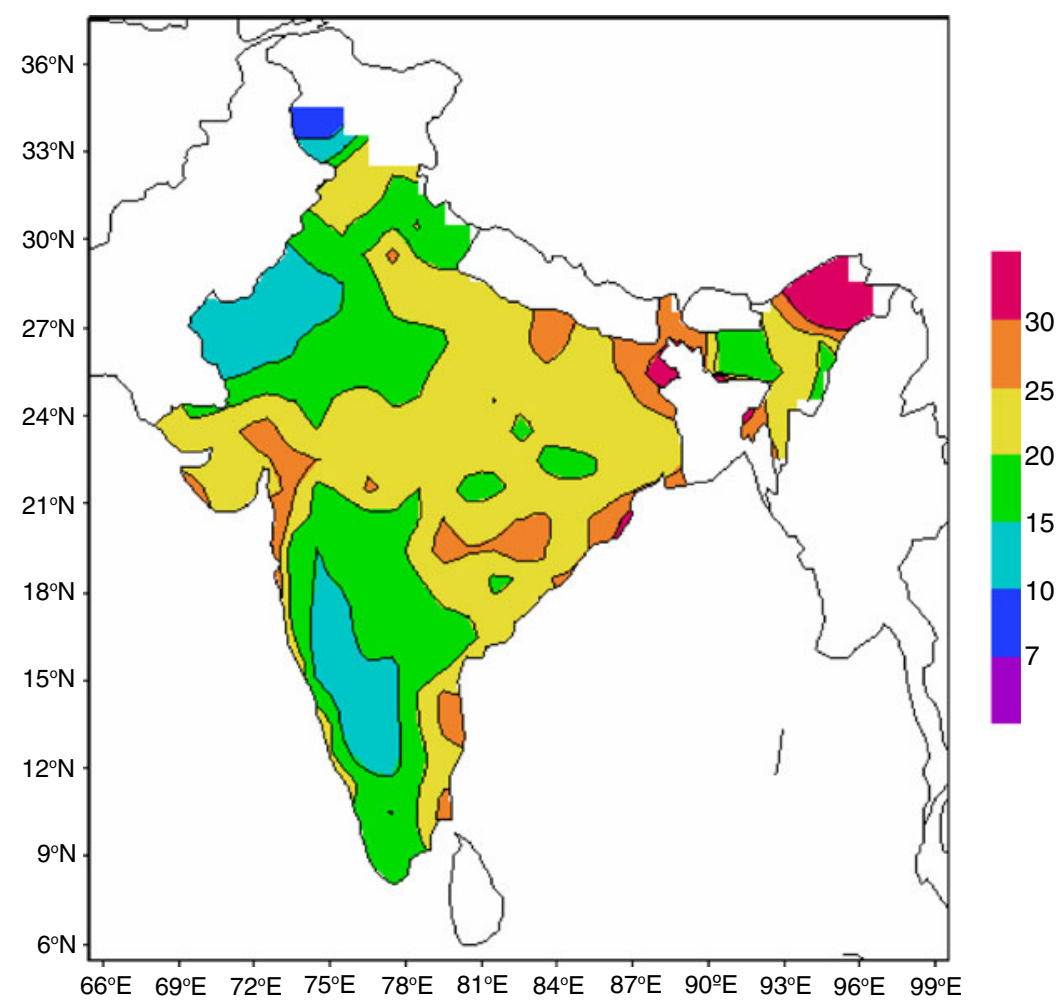

Figure 10. Extreme values for 25-year return period. 


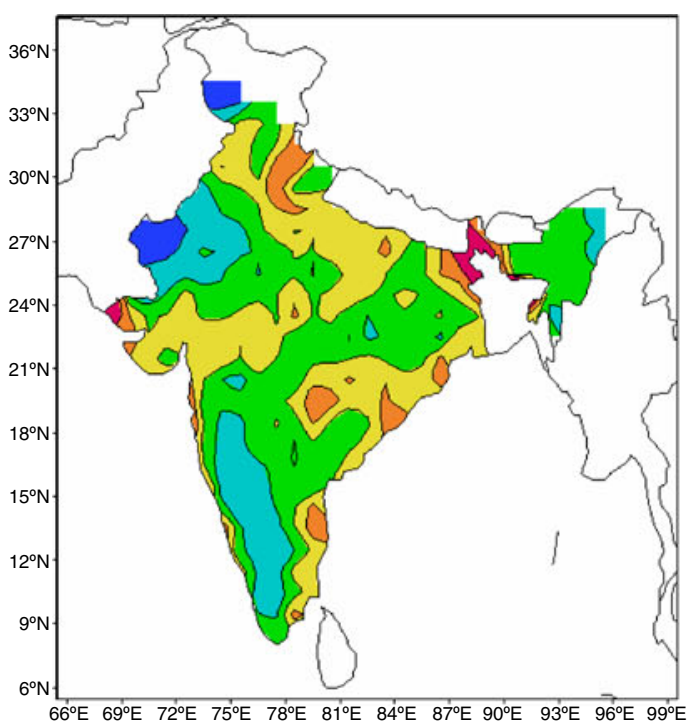

1951-1960

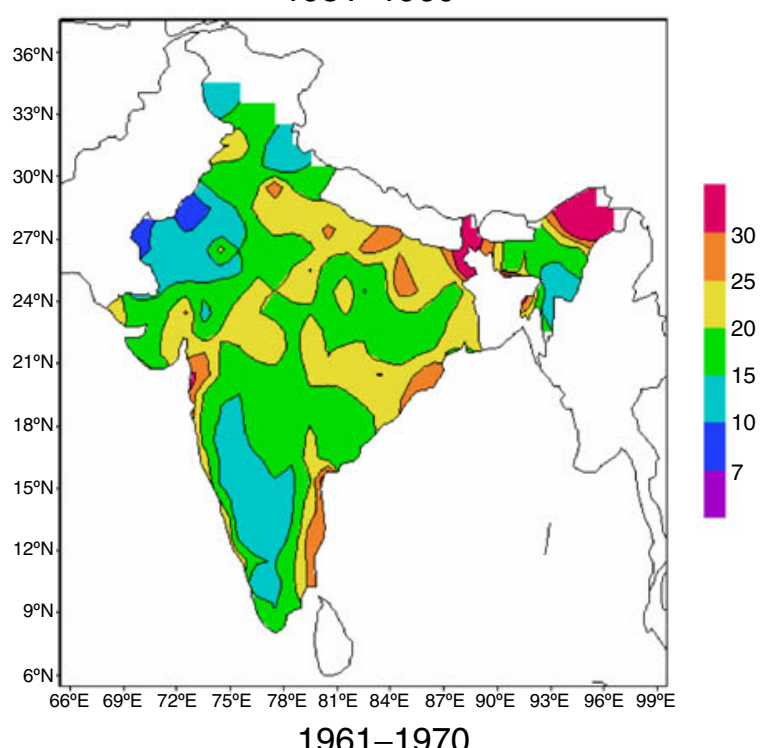

1961-1970
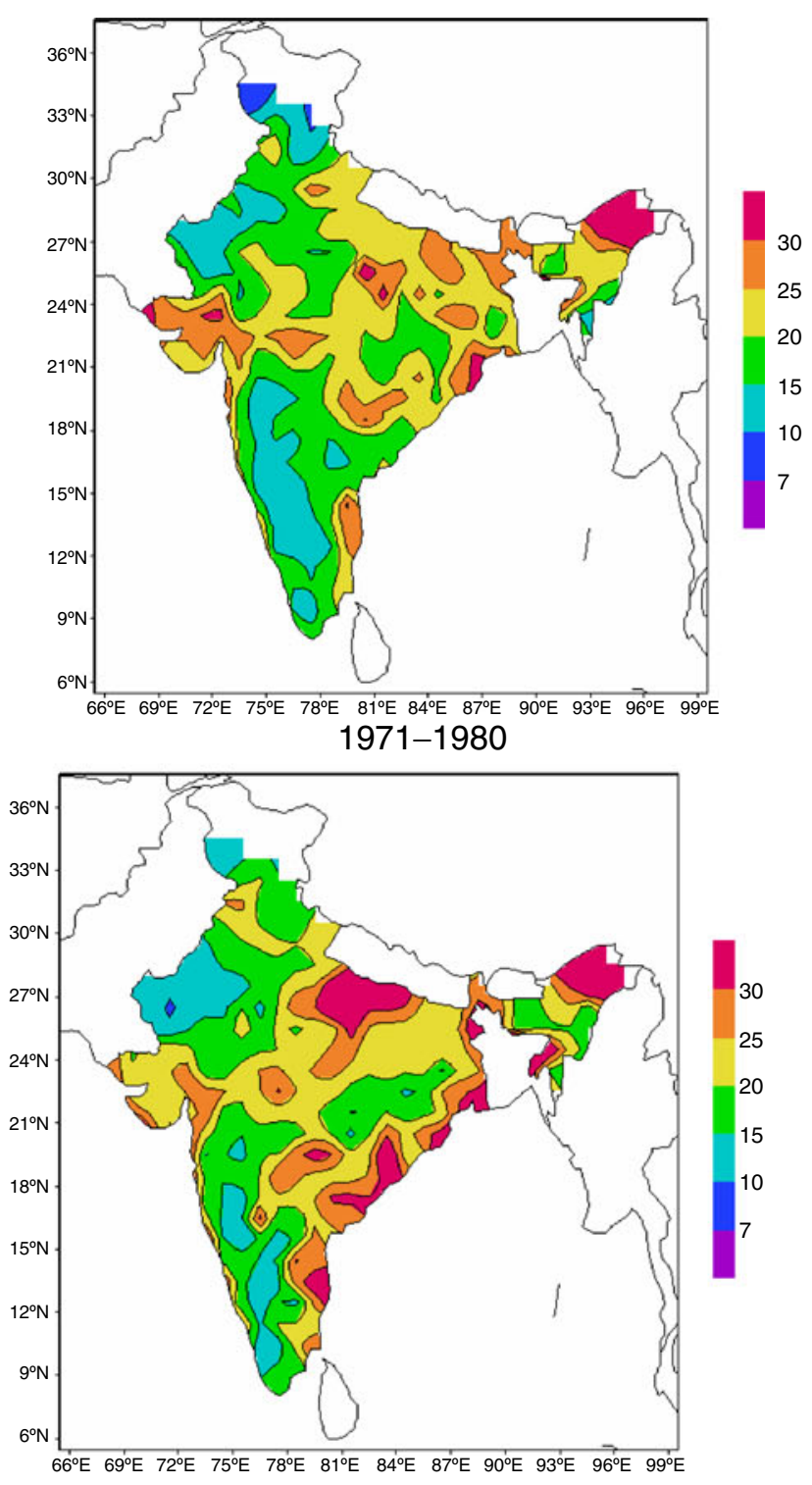

1981-1990

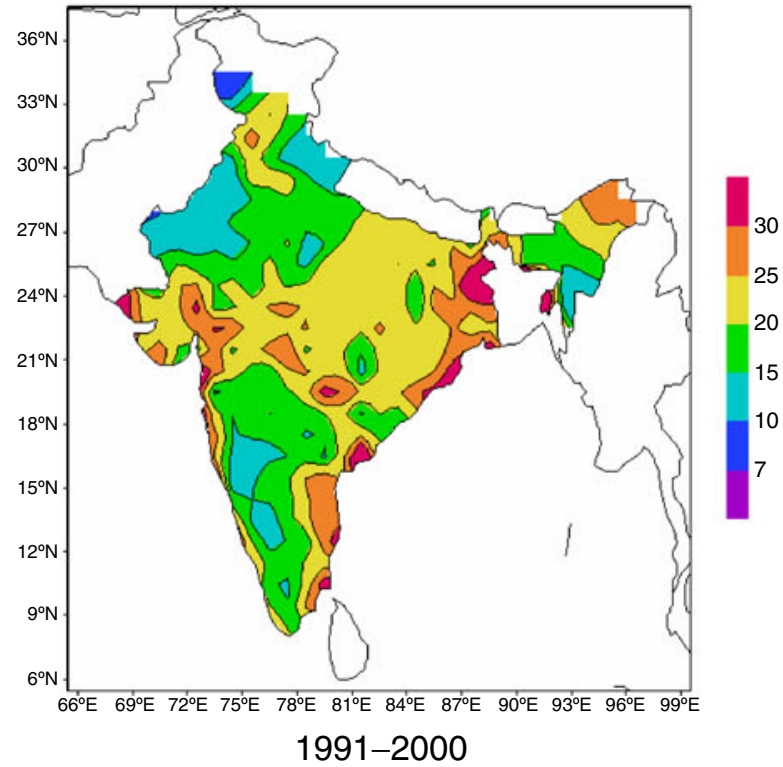

Figure 11. Decadal variability of extreme values $(\mathrm{cm})$ for 25 -year return period. 


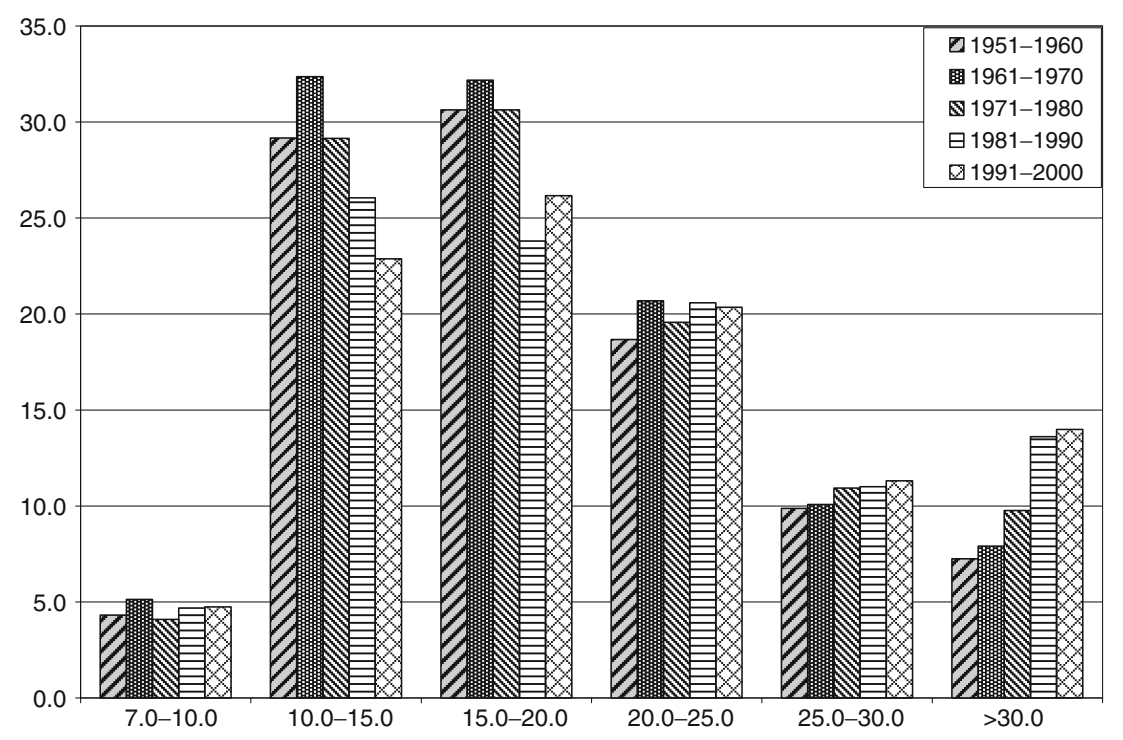

Figure 12. Percentage frequencies of extreme values $(\mathrm{cm})$ for 25-year return period in different range for each of the decades.

and some other isolated areas. The parametric test using linear regression helps to find out the rate of increase in 100 years and these are shown in figure 9. Significant decrease both in intensity and frequency of extreme rainfall have been observed over Chattisgarh, Jharkhand and some parts of north India.

The extreme values for 25 return periods showed large variation (figure 10). Values of a 25-year return period varied from $10 \mathrm{~cm}$ over Rajasthan, parts of north interior Karnataka and Marathwada to $30 \mathrm{~cm}$ over West Bengal, Orissa and parts of north east India. To find the change in flood risk, we have studied the decadal variability of a 25 -year return period. Temporal variability in extremes has also been analysed in fixed decades from 19611970, 1971-1980, 1981-1990 and 1991-2000 earlier by Fowler and Kilsby (2003) for investigating the flood risk in the United Kingdom although large uncertainty prevails along with change of time. Figure 11 shows the decadal variability of extreme values $(\mathrm{cm})$ for a 25-year return period for the decades 1951-1960, 1961-1970, 1971-1980, 19811990 and 1991-2000. In the decade 1991-2000, the probability of occurrence of extreme values of more than $25 \mathrm{~cm}$ or more was found along the northern parts of the west coast, throughout the eastern coast, West Bengal and Gujarat regions. Figure 12 brings out the percentage frequencies of extreme values $(\mathrm{cm})$ for a 25-year return period in different ranges for each of the decades. Percentage frequencies for different ranges are calculated from the decadal return values of all the 2249 rain gauge stations. It is clear that frequency of extreme values greater than $30 \mathrm{~cm}$ were more in the recent two decades, viz., 1981-1990 and 1991-2000. The evidence of increase in flood risk during the recent decades is clearly noticed.

\section{Conclusions}

This study reveals the noticeable changes in the extreme rainfall events that occurred over India in the past century. The country experienced large spatial variations in annual normal rainy days. Annual normal rainy days varied from 10 days over extreme western parts of Rajasthan to the high frequency of 130 days over northeastern parts of the country. The non-parametric test as well as the linear trend analysis identified decreasing trends in the frequency of wet days in most parts of the country. Trend analysis of frequency of rain days, rainy days and heavy rainfall days showed significant decreasing trends over central and many parts of north India; and increasing trends over peninsular India. Also, the great desert areas of the country have experienced increased number of wet days. Analysis of one-day extreme rainfall series has shown that the intensity of extreme rainfall has increased over coastal Andhra Pradesh and its adjoining areas, Saurashtra and Kutch, Orissa, West Bengal, parts of northeast India, and east Rajasthan. Significant decrease in intensity as well as frequency of extreme rainfall have been observed over Chattisgarh, Jharkhand and some parts of north India. The flood risk also increased significantly over India. The flood risk was more in the decades 1981-1990, 1971-1980 and 1991-2000. The increase of flood risk has increased during the last two decades mostly over the eastern coast, West 
Bengal, east Uttar Pradesh, Gujarat and Konkan region.

\section{Acknowledgements}

The authors thank the Director General of Meteorology, India Meteorological Department for his encouragement and support in completing this work. They also thank the referees for their fruitful suggestions and comments to improve the quality of the paper.

\section{References}

Burn D H and Hag-Elnur M A 2002 Detection of hydrologic trend and variability; J. Hydrol. 255 107-122.

Fowler H J and Kilsby C G 2002 Precipitation and the North Atlantic Oscillation: A study of climatic variability in Northern England; Int. J. Climatol. 22 843-866.

Fowler H J and Kilsby C G 2003 A regional frequency analysis of United Kingdom extreme rainfall from 1961 to 2000; Int. J. Climatol. 23 1313-1334.

Fowler H J, Kilsby C G and O'Connell P E 2000 A stochastic rainfall model for the assessment of regional water resource systems under changed climatic conditions; Hydrol. Earth Syst. Sci. 4 263-282.

Galambos J 1987 The Asymptotic Theory of Extreme Order Statistics, 2nd edn. (Melbourne, Florida: Krieger).

Goswami B N, Venugopal V, Sengupta D, Madhusoodanan M S and Xavier P K 2006 Increasing trend of extreme rain events over India in a warming environment; Science 314 1442-1445.

Guhathakurta P 2007 Highest recorded point rainfall over India; Weather $\mathbf{6 2} 12$.

Guhathakurta P and Rajeevan M 2008 Trends in rainfall pattern over India; Int. J. Climatol. 28 1453-1469.
Hirsch R M, Slack J R and Smith R A 1982 Techniques of trend analysis for monthly water quality data; Water Resour. Res. 18 107-121.

Hosking J R M, Wallis J R and Wood E F 1985 Estimation of the generalized extreme value distribution by the method of probability weighted moments; Technometrics $\mathbf{2 7}$ 251-261.

IPCC 2007 Fourth Assessment Report (AR4) of the United Nations Intergovernmental Panel on Climate Change.

Jenkinson A F 1955 The frequency distribution of the annual maxima (or minima) values of meteorological elements; Quart. J. Roy. Meteor. 81 158-171.

Kendall M G 1975 Rank Correlation Methods (London: Griffin).

Lettenmaier D P, Wood E F and Wallis J R 1994 Hydroclimatological trends in the continental United States, 1948-1988; J. Climate 7 586-607.

Mann H B 1945 Nonparametric tests against trend; Econometrica 13 245-259.

Rajeevan M, Bhate J and Jaswal A K 2008 Analysis of variability and trends of extreme rainfall events over India using 104 years of gridded daily rainfall data; Geophys. Res. Lett. 35 L18707, doi: 10.1029/2008GL035143.

Rakhecha P R and Pisharoty P R 1996 Heavy rainfall during monsoon season: Point and spatial distribution; Curr. Sci. 71 177-186.

Rakhecha P R and Soman M K 1994 Trends in the annual extreme rainfall events of 1 to 3 days duration over India; Theor. Appl. Climatol. 48(4) 227-237.

Sen Roy S and Balling R C 2004 Trends in extreme daily precipitation indices in India; Int. J. Climatol. 24 $457-466$.

Sinha Ray K C and Srivastava A K 2000 Is there any change in extreme events like drought and heavy rainfall?; Curr. Sci. 79(2) 155-158.

Stephenson D B, Rupa Kumar K, Doblas-Reyes F J, Royer J F, Chauvin F and Pezzulli S 1999 Extreme daily rainfall events and their impact on ensemble forecasts of the Indian monsoon; Mon. Weather Rev. 127 1954-1966. 